\title{
Hybrid Modification of Stone Mastic Asphalt with Cellulose and Basalt Fiber
}

\author{
You Huang $\mathbb{D}^{1},{ }^{1}$ Zhaohui Liu, ${ }^{1}$ Li Liu $\mathbb{D}^{1},{ }^{1}$ Yunbao Zhang, ${ }^{1,2}$ and Qingxiang Xu ${ }^{1}$ \\ ${ }^{1}$ School of Traffic and Transportation Engineering, Changsha University of Science and Technology, Changsha 410114, China \\ ${ }^{2}$ Department of Transportation of Hunan Province, Changsha 410116, China \\ Correspondence should be addressed to Li Liu; 805296712@qq.com
}

Received 2 June 2020; Revised 23 August 2020; Accepted 15 September 2020; Published 22 September 2020

Academic Editor: Meng Guo

Copyright (c) 2020 You Huang et al. This is an open access article distributed under the Creative Commons Attribution License, which permits unrestricted use, distribution, and reproduction in any medium, provided the original work is properly cited.

In this study, cellulose and basalt fiber were introduced simultaneously to stone mastic asphalt (SMA) to investigate the effects of hybrid modification on performance improvement of asphalt mixture. The study consists of three parts. The first part investigated material properties of cellulose and basalt fiber, including microscope electrical scanning. The second part conducted a series of tests to evaluate the effects of different combinations of cellulose and basalt fiber on performance. With a total addition of fiber $0.4 \%$ by the weight of mixture, five different cellulose-basalt fiber ratios, $0: 4,1: 3,2: 2,3: 1$, and $4: 0$, were introduced to the asphalt mixtures. A series of tests including draindown, permanent deformation, low temperature bending, beam fatigue, and moisture damage resistance were conducted. In the final part, a benefit-cost ratio was designed to help determine the optimum cellulose-basalt fiber combination in the economic aspect. Results show that material properties of the two fibers are very different, including thermostability, modulus, surface, and microstructure, especially oil absorption. In general, all samples with fibers outperformed the control group in all the performance tests. Specifically, cellulose fiber improved draindown, ductility, and fatigue more significantly, whilst basalt fiber has more influence on improving permanent deformation, deflection strength, and stress sensitivity. Equal portion of cellulose and basalt fiber has the best moisture damage resistance. The mechanisms of the two fibers are different, resulting in different performance improvements on asphalt mixtures. Overall, an appropriate combination of the two fibers would produce paving materials with more balanced performance in an economical way.

\section{Introduction}

Asphalt mixture is made of bitumen, aggregates, and filler, of which the properties are very sensitive to many factors including temperature, load-time, moisture, and stress level. Researchers and engineers are constantly trying to improve the performance of asphalt mixture. Fibers have been used to improve paving materials for decades in many parts of the world and are gaining more attention due to their effects. Researches have stated that fibers can significantly improve asphalt mixture performances in one way or another [1]. The finely divided fiber provides a high surface area per unit weight so that mixtures with fiber showed an increase in the optimum binder content [2]. Another function that fiber plays is to reinforce the asphalt mixture, which carries more tensile load and prevent propagation of cracks [3]. In all, fiber changes the viscoelasticity of modified asphalt mixture, improves the dynamic modulus, moisture susceptibility, creep compliance, fatigue life, and rutting resistance, and reduces reflective cracking of asphalt pavement [4-11].

Although fibers have many aforementioned advantages in asphalt concrete, economy should be taken into consideration. Studies showed that the cost of the fiber mixture was about $11 \%$ higher than the cost of control mixture, and this increased cost could be justified by an increase in the service life of $0.9 \sim 1.1$ years [12]. However, they may not be cost-effective if the improvement is not substantial. Currently, fibers have shown obvious performance promotion in gap graded asphalt mixtures, like SMA (stone matrix asphalt). SMA is a type of hot mix asphalt consisting of a coarse aggregate skeleton and a high binder content mortar. As the stone-on-stone structure improves rutting resistance, the 
high asphalt content brings in problems like draindown or bleeding during the processes of production, storage, transportation, and paving $[13,14]$. By far, the most common practice is to introduce fiber into the asphalt mixture to prevent draindown or bleeding.

Cellulose fiber is plant-based fiber most commonly from woody plants or recycled papers. This kind of fiber has a rough texture, porous surface, and diameter varied along the length $[15,16]$. As a result, it has fairly high absorption of asphalt. It is this nature that helps holding higher binder contents in mixtures. Cellulose fibers in asphalt mixtures allow asphalt content to be increased while drastically decreasing draindown/bleeding of asphalt binder [17-19]. Cellulose fibers are widely available and inexpensive and may be provided either in loose form or in pellets.

Basalt fiber is a mineral fiber manufactured by melting crushed basalt, a hard, dense and stable igneous rock, then physically forming fibers by spinning or extruding at about $1500^{\circ} \mathrm{C}$. Basalt fiber has high elastic modulus and tensile strength and has no toxic reaction with air or water. When in contact with chemicals, they produce no chemical reactions that may damage health or environment [20]. As it is strong and stable, it makes a perfect reinforcement material for infrastructure. But due to the relative smooth surface, it is not as absorptive as cellulose. High price is another disadvantage that may hinder its application in engineering projects. Some scholars also pointed out the damage basalt fiber may have on vehicle tires [21].

Most studies focusing on fiber-reinforced paving materials generally investigate the effect of fiber separately. This paper introduced an idea of hybrid modification of asphalt mixture by introducing cellulose and basalt fiber simultaneously into SMA so as to take advantages of both fibers to produce more balanced designed paving material. Properties of the two fibers were investigated first. Then, draindown test, wheel tracking test at high temperature, low-temperature bending, beam fatigue test, and moisture damage test were conducted to evaluate the performance of SMA with different fiber combinations. Finally, an economic solution is provided to get optimum benefit-cost efficiency taking consideration of economy.

\section{Material Property Test}

The basic mechanical properties of the basalt fiber are listed in Table 1. The cellulose fiber used in this study is $6 \mathrm{~mm}$ long, with ash content about $17.6 \%$. Other properties including oil absorption, water absorption, and $\mathrm{pH}$ will be tested and shown in Section 2.1. Three replicates were used for each test, and results were averaged for analysis.

2.1. Thermostability Test. Technically, there are two approaches of introducing fiber: wet process and dry process. In the wet approach, fibers are blended with asphalt binder first and then blended into mixture, while in the dry approach, fiber is mixed with the aggregate before adding asphalt binder. Generally, the dry process is preferred as it is easy to perform and fiber can be distributed evenly in the mixture [24]. During the production of SMA, the temperature of aggregates can easily reach $170 \sim 180^{\circ} \mathrm{C}$. If styrenebutadiene-styrene- (SBS-) modified asphalt is used, which is the normal case in SMA production, the blending temperature could be even higher. As a result, stability of fiber at a high temperature is a property worth looking into. In thermostability tests, randomly weighted samples of the two fibers were first kept in $50^{\circ} \mathrm{C}$ for $4 \mathrm{~h}$ to dry up. Then, they were heated to $165^{\circ} \mathrm{C} / 200^{\circ} \mathrm{C}$ and kept for $2 \mathrm{~h} / 5 \mathrm{~h}$. The mass loss was recorded as an indication of thermostability as is listed in Table 2.

The results show that mass loss of cellulose is much higher than that of basalt fiber, indicating that basalt fiber is much more durable than cellulose. Mass loss of basalt fiber was very small, generally less than $1 \%$. Cellulose was not as stable as basalt fiber in high temperature, and the mass loss was much higher, about $5 \%$ at $165^{\circ} \mathrm{C}$ for $2 \mathrm{~h}$. The mass loss increased as temperature and duration increased, up to nearly $12 \%$ at $200^{\circ} \mathrm{C}$ for $5 \mathrm{~h}$. In Figure 1 , it is also seen that the appearance of basalt fiber does not change with heating time, while the color of cellulose under $200^{\circ} \mathrm{C} / 5 \mathrm{~h}$ becomes darker and more curled than that under $200^{\circ} \mathrm{C} / 2 \mathrm{~h}$. In general, the mass loss of cellulose is 20 times that of basalt fiber. The relative high mass loss in cellulose raises the consciousness of strict temperature control during the production of asphalt mixtures with fiber. It is also implied that adding basalt fiber to replace some cellulose can decrease fiber loss in mixture production.

2.2. Compatibility Test. Compatibility with asphalt cement is a key factor of fiber to enhance the asphalt mixture performance. Evaluation of compatibility includes $\mathrm{pH}$, oil absorption, and stripping test. The $\mathrm{pH}$ test is an indication of chemical bond of asphalt with fiber, while oil absorption is an indication of physical bond. The stripping test is a performance-related evaluation of bond between asphalt and fiber.

The $\mathrm{pH}$ test is typically done by soaking fiber in distilled water and measuring the $\mathrm{pH}$ of the water with $\mathrm{pH}$ meter. $5 \mathrm{~g}$ dry cellulose and basalt fiber were put into $100 \mathrm{ml}$ distilled water, respectively, and stirred for a while to disperse the fiber for full contact with water. After a rest of 30 minutes, fibers were taken out and $\mathrm{pH}$ of the water was measured. Test results showed that $\mathrm{pH}$ of water with cellulose was 7.24, and $\mathrm{pH}$ of water with basalt fiber was 7.92. Both fiber are weak alkaline, but the $\mathrm{pH}$ of basalt fiber is a little higher because the basalt fiber is mainly composed of $\mathrm{SiO}_{2}, \mathrm{Al}_{2} \mathrm{O}_{3}$, and $\mathrm{FeO}_{\mathrm{x}}$, which produce alkaline chemical reaction. According to the bond theory of asphalt with aggregates, it is the acidic components of asphalt that reacts with alkali components of aggregates to form water insoluble salts which become a very strong bond. Hicks stated that chemical reaction between most asphalts and acidic aggregates is weaker compared with alkali aggregates [25]. As such, both fibers have a good potential of chemical bond with asphalt.

Oil absorption is an important index to test the fiber's ability of holding asphalt due to the surface texture (e.g., smoothness and porosity) of fibers. $5 \mathrm{~g}$ dry cellulose and 
TABLE 1: Basic properties of basalt fiber.

\begin{tabular}{lcc}
\hline Item & Value & Standards \\
\hline Density $\left(\mathrm{g} / \mathrm{cm}^{3}\right)$ & $2.56 \sim 3.05$ & ASTM D3800-16 [22] \\
Diameter $(\mu \mathrm{m})$ & 13 & ASTM D3800-16 [22] \\
Length $(\mathrm{mm})$ & 6 & \\
Tensile strength $(\mathrm{MPa})$ & $4100 \sim 4830$ & \\
Elastic modulus $(\mathrm{GPa})$ & $90 \sim 110$ & ASTM D5034-17 [23] \\
Elongation rate $(\%)$ & $3.0 \sim 3.3$ & \\
pH & 9.72 & \\
\hline
\end{tabular}

TABLE 2: Mass loss of cellulose and basal fiber.

\begin{tabular}{|c|c|c|c|c|c|}
\hline Fiber & Test procedure & Mass before heat $(\mathrm{g})$ & Mass after heat $(\mathrm{g})$ & Mass loss (\%) & Visual change of fiber \\
\hline \multirow{4}{*}{ Basalt fiber } & $165^{\circ} \mathrm{C}, 2 \mathrm{~h}$ & 1.0180 & 1.0155 & 0.246 & \multirow{4}{*}{ No change. } \\
\hline & $165^{\circ} \mathrm{C}, 5 \mathrm{~h}$ & 1.0442 & 1.0416 & 0.249 & \\
\hline & $200^{\circ} \mathrm{C}, 2 \mathrm{~h}$ & 1.0334 & 1.0269 & 0.629 & \\
\hline & $200^{\circ} \mathrm{C}, 5 \mathrm{~h}$ & 1.0118 & 1.0053 & 0.642 & \\
\hline \multirow{4}{*}{ Cellulose fiber } & $165^{\circ} \mathrm{C}, 2 \mathrm{~h}$ & 1.0120 & 0.9624 & 4.901 & \multirow{4}{*}{ Fiber curl, and color of surface becomes darker. } \\
\hline & $165^{\circ} \mathrm{C}, 5 \mathrm{~h}$ & 1.0563 & 0.9829 & 6.949 & \\
\hline & $200^{\circ} \mathrm{C}, 2 \mathrm{~h}$ & 1.0248 & 0.9278 & 9.465 & \\
\hline & $200^{\circ} \mathrm{C}, 5 \mathrm{~h}$ & 1.0007 & 0.8809 & 11.972 & \\
\hline
\end{tabular}

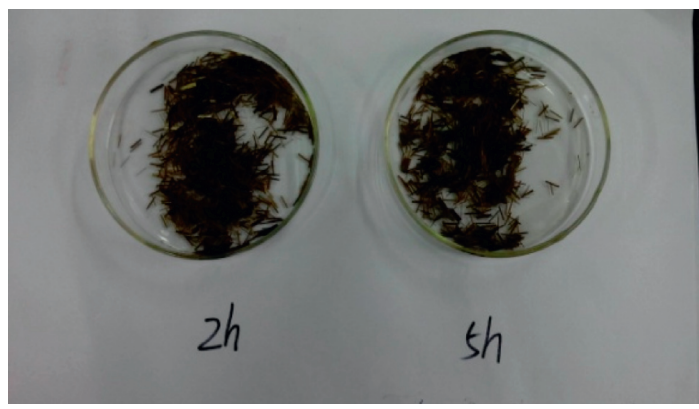

(a)

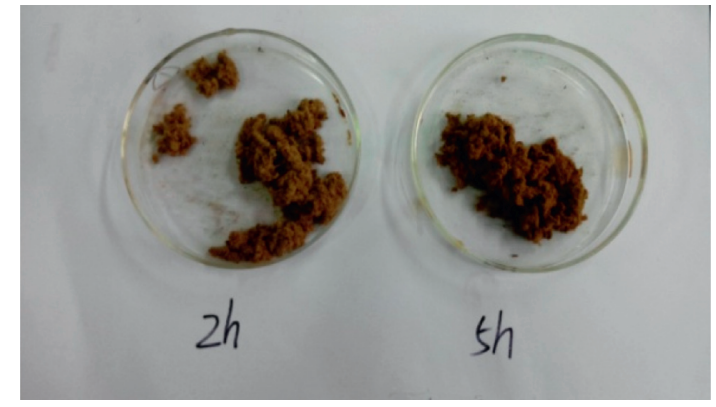

(b)

Figure 1: Visual change of fibers after the thermostability test. (a) Basalt fiber $\left(200^{\circ} \mathrm{C}\right)$. (b) Cellulose $\left(200^{\circ} \mathrm{C}\right)$.

basalt fiber were put in $100 \mathrm{ml}$ mineral spirit (kerosene), respectively, and stirred for a while for full contact. After 30 minutes' rest, the fibers were taken out and put into a $0.25 \mathrm{~mm}$ sieve and shaken gently for $10 \mathrm{mins}$ to get rid of excessive mineral spirit and then weighed. The mass change in terms of how many times the mass of fiber was used to evaluate absorption. The test results of cellulose and basalt fiber were $683.4 \%$ and $145 \%$, respectively. It was clearly shown that oil absorption of cellulose is much higher, nearly 5 times that of basalt fiber. High absorption of cellulose is a very good complement for basalt fiber to help hold asphalt and solves problems like draindown and bleeding in SMA. Similar tests were done with distilled water, and the absorption was $510 \%$ and $96 \%$ for cellulose and basalt fiber, respectively. Although the absorptions of oil were fairly larger than water for both fibers, higher oil absorption of cellulose indicates possible higher vulnerability of water deterioration of asphalt pavement with cellulose. In this sense, replacing some cellulose with basalt fiber could reduce the risk of moisture damage and increase the service life of asphalt pavement.

The stripping test of bond between asphalt and fiber was designed similarly to the "boiling water test" for bond between asphalt and aggregate. $4 \mathrm{~g}$ cellulose or basalt fiber was put in $100 \mathrm{~g}$ asphalt separately and stirred for a while for full contact. Another sample with $2 \mathrm{~g}$ cellulose and $2 \mathrm{~g}$ basalt fiber was also prepared. The fibers covered with asphalt were then put onto a $0.25 \mathrm{~mm}$ sieve and kept at $165^{\circ} \mathrm{C}$ for $1 \mathrm{~h}$ to let excessive asphalt draindown. After that, samples were cooled down to room temperature. Randomly selected fibers covered with asphalt were put into boiling water for 3 minutes. At last, pick the fiber out, observe the surface, and estimate the stripped area of asphalt. No strip was observed in the $4 \mathrm{~g}$ cellulose, $2 \mathrm{~g}$ cellulose, and $2 \mathrm{~g}$ basalt fiber; but about 6\% $10 \%$ area was stripped in the $4 \mathrm{~g}$ basalt fiber. Results indicated that the bond of cellulose with asphalt was stronger than that of basalt fiber. Combination of cellulose and basalt fiber demonstrated similarly excellent bond as cellulose. 
2.3. Microscope Detection. As mentioned before, the surface of cellulose and basalt fiber is very different, which may influence the interface between asphalt and fiber. The absorption test and bond test above verified that cellulose has a better absorption and better bond with asphalt than basalt fiber. To get a more direct comparison of asphalt absorption of the two fibers, an environmental scanning electron microscope (ESEM) was employed to detect the microscale state of cellulose and basalt fiber mixed with asphalt, as is shown in Figure 2.

In Figure 2(a), basically, the surface of basalt fiber is smooth with a thin and evenly distributed asphalt film covering the basalt fiber along the length. On contrast, Figure 1(b) shows that there was a lot more asphalt adhered to the cellulose. As the asphalt molecules align near to the internal and external surfaces of cellulose filament, they increase the thickness of asphalt membrane and effectively increase the bond between asphalt and cellulose. Furthermore, there is a "root structure" that forms at the root of cellulose, which is believed to enhance the bond between asphalt and the fiber greatly. It is visually clearly shown in the pictures that cellulose absorbs much more asphalt than the basalt fiber does and forms stronger bond with asphalt.

The properties above indicate that cellulose and basalt fiber have different material properties. Comparatively, cellulose has better absorption of and stronger bond with asphalt material, while basalt fiber demonstrates better thermal stability and mechanical behavior (higher elastic modulus and higher tensile strength). It is preliminarily hypothesized that the introduction of both fibers will complement each other and leads to more balanced performances of asphalt mixture than only one fiber.

\section{Performance Test}

3.1. Mixture Design and Specimen Preparation. Performance tests were designed to test the hypothesis that hybrid introduction of both cellulose and basalt fiber would result in asphalt mixture with more balanced performance. SMA-13 (stone mastic asphalt with nominal maximum aggregate size $13 \mathrm{~mm}$ ) specimens were prepared as per the Marshall mixture design method [26]. The Marshall mixture design method is a classical method of designing asphalt mixture mainly based on volumetric properties together with mechanical properties. First, asphalt mixtures with different asphalt contents (usually 5 asphalt contents) were prepared, and then, a series of tests are conducted to inquire volumetric parameters: volumetric voids (VVs), voids of mineral aggregates (VMAs), and voids of mineral aggregates that are filled with asphalt (VFA), as well as mechanical properties: Marshall stability and flow number and dynamic stability of the prepared asphalt mixtures. Change of volumetric properties and mechanical properties against asphalt content is plotted and fitted by second-order polynomial, and the optimum asphalt content (OAC) is determined as the asphalt content that gives the best volumetric and mechanical properties based on a comprehensive evaluation. The gradation of basalt aggregates is shown in Figure 3. Properties of styrene-butadiene-styrene- (SBS-) modified asphalt are listed in Table 3.

The cellulose and basalt fiber were both $6 \mathrm{~mm}$ long. The total introduction of fiber was $0.4 \%$ of the mixture by weight as most literatures and practices recommended [1, 6, 27]. Five combinations of cellulose and basalt fiber were designed with the portions of cellulose to basalt fiber, $0: 4,1: 3,2: 2,3$ : 1 , and $4: 0$, by weight. A control group without any fiber was marked as $0: 0$. As fiber portion changes, the OAC was anticipated to change too. Marshall tests were conducted to determine OAC for each fiber combination. OAC and volumetric properties are listed in Table 4.

Generally, OAC increases with cellulose. This is because cellulose has strong asphalt absorption. At the same time, the volumetric properties also changed. For example, the VV and VMA increased first and then began to decrease; on contrary, VFA declined a little but went up afterwards. All these changes are mainly due to the asphalt content change caused by different combinations of fibers. Another contribution is the volumetric difference of different fiber combinations. The addition of fiber is controlled by weight, but cellulose and basalt fiber have different densities, meaning volume of fibers are different, which could in turn affect the volumetric properties of SMA specimen.

3.2. Draindown Test. A draindown test was carried out as per ASTM D6390 [28]. A certain amount (about $1 \mathrm{~kg}$ ) of loose SMA was put in a glass beaker after mixing with fiber. The covered beaker was held in an oven at $185^{\circ} \mathrm{C} \pm 1^{\circ} \mathrm{C}$ for about $60 \mathrm{~min} \pm 1 \mathrm{~min}$. Then the beaker was turned over, allowing the mix to fall into a tared bowl. The difference of mass, expressed in the percentage of the original mass, was the draindown loss. The upper-limit of draindown loss is $0.3 \%$. Four replicates were tested, and results were averaged for analysis. Test results are shown in Figure 4.

The results were pretty straight forward, draindown loss decreased with higher portion of cellulose, and this is a direct sign that cellulose can hold asphalt better than basalt fiber. More cellulose would improve the asphalt draindown in SMA. SMA without fiber showed much higher draindown loss, about $0.35 \%$, which failed the criterion of $0.3 \%$. A onetail $t$ test was carried out to check the difference between different fiber combinations. The null hypothesis was that the draindown of different fiber combinations was the same. The $P$ value was calculated and compared with the critical value of 0.05 to reject or accept the null hypothesis. In this study, $P \leq 0.05$ means the results of different fiber combinations are statistically different. As listed in Table 5, most of the test results are significantly different from each other. Especially, the control group $(0: 0)$ is significantly different from all other samples with fibers, meaning that fibers, 


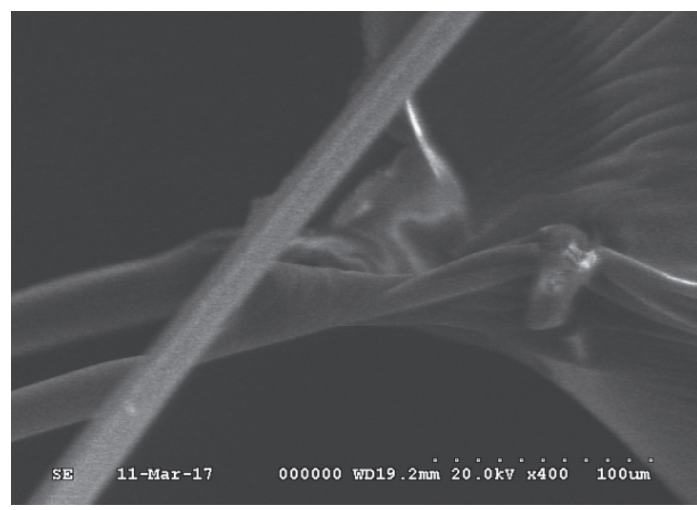

(a)

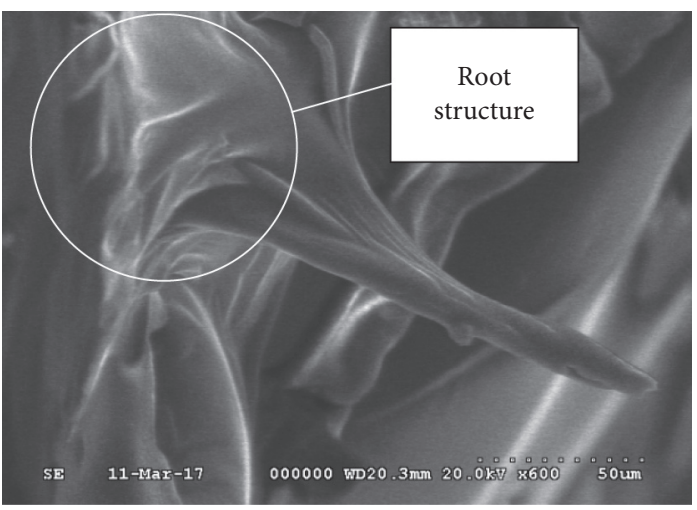

(b)

FIgUre 2: Image of ESEM (magnified by 500 times). (a) Basalt fiber. (b) Cellulose.

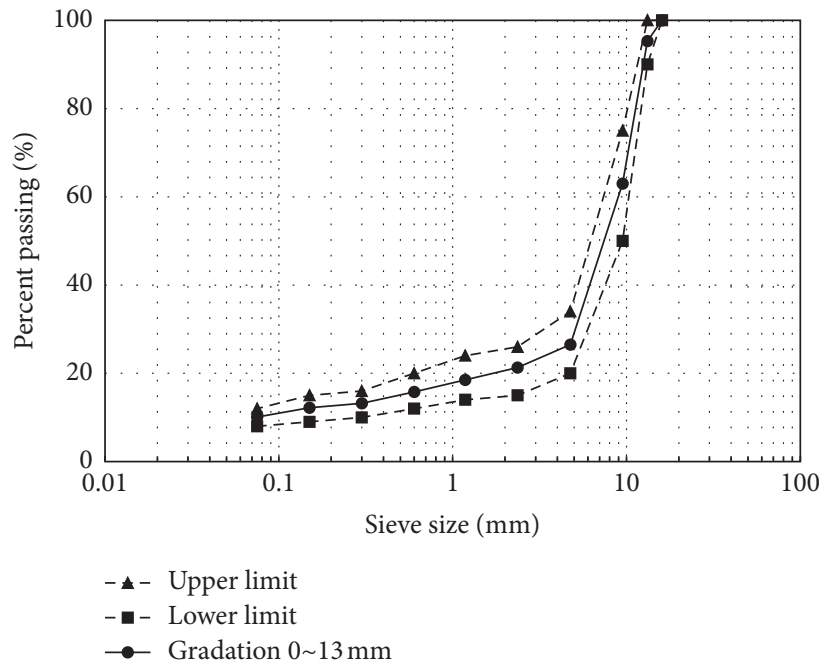

Figure 3: Gradation of SMA.

TABle 3: Physical properties of base asphalt.

\begin{tabular}{lcc}
\hline Properties & Values & Standards \\
\hline Specific gravity at $25^{\circ} \mathrm{C}\left(\mathrm{g} / \mathrm{cm}^{3}\right)$ & 1.03 & ASTM D70 \\
Penetration at $25^{\circ} \mathrm{C}(1 / 10 \mathrm{~mm})$ & 55 & ASTM D5M \\
Softening point $\left({ }^{\circ} \mathrm{C}\right)$ & 50.1 & ASTM D36 M \\
Flash point $\left({ }^{\circ} \mathrm{C}\right)$ & 298 & ASTM D92 \\
Ductility at $25^{\circ} \mathrm{C}(\mathrm{cm})$ & $>100$ & ASTM D113 \\
Viscosity at $60^{\circ} \mathrm{C}(\mathrm{Pa} \cdot \mathrm{s})$ & 876 & ASTM D4402 \\
Loss on heating $(\%)$ & 0.042 & ASTM D6M \\
\hline
\end{tabular}

TABLE 4: OAC and volumetric properties of SMA with different fiber combinations.

\begin{tabular}{lcccc}
\hline Cellulose : basalt & OAC (\%) (asphalt-aggregate ratio) & VV (\%) & VMA (\%) & VFA (\%) \\
\hline $0: 4$ & 5.9 & 3.6 & 16.5 & 79.4 \\
$1: 3$ & 6.0 & 3.8 & 16.6 & 77.1 \\
$2: 2$ & 6.1 & 3.9 & 17.0 & 77.6 \\
$3: 1$ & 6.1 & 3.2 & 16.7 & 80.8 \\
$4: 0$ & 6.2 & 3.4 & 17.2 & 79.0 \\
$0: 0$ & 5.4 & 4.2 & 16.0 & 75.3 \\
\hline
\end{tabular}




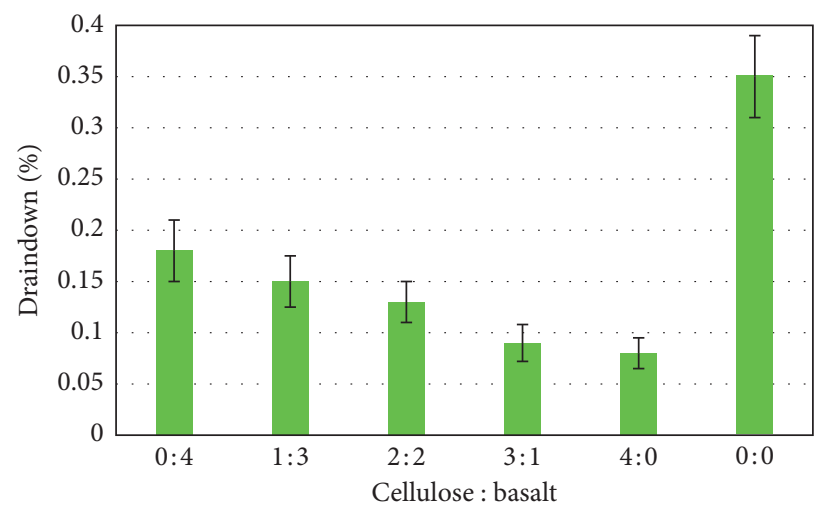

FIgURe 4: Draindown test of SMA with different fiber combinations.

TABle 5: $P$ values of draindown of different fiber combinations.

\begin{tabular}{lcccccc}
\hline Cellulose : basalt & $0: 4$ & $1: 3$ & $2: 2$ & $3: 1$ & $4: 0$ & $0: 0$ \\
\hline $0: 4$ & - & 0.173 & 0.067 & $\mathbf{0 . 0 1 9}$ & $\mathbf{0 . 0 1 3}$ & $\mathbf{0 . 0 0 9}$ \\
$1: 3$ & - & - & 0.193 & $\mathbf{0 . 0 1 9}$ & $\mathbf{0 . 0 1 7}$ & $\mathbf{0 . 0 0 5}$ \\
$2: 2$ & - & - & - & 0.06 & $\mathbf{0 . 0 4 2}$ & $\mathbf{0 . 0 0 4}$ \\
$3: 1$ & - & - & - & - & 0.336 & $\mathbf{0 . 0 0 2}$ \\
$4: 0$ & - & - & - & - & - & $\mathbf{0 . 0 0 7}$ \\
$0: 0$ & - & - & - & - & - & - \\
\hline
\end{tabular}

whether cellulose or basalt fiber or the combination of both, has significant improvement on the draindown of asphalt mixture.

3.3. Permanent Deformation Test. The main advantage of SMA lies in its excellent rutting resistance. The wheel tracking test was carried out to compare the permanent deformation of SMA with different fiber combinations at high temperature. Wheel tracking test simulates traffic moving on pavement to test the permanent deformation resistance of asphalt mixture at high temperature as per JTG E20-2011[29]. The test temperature was set at $60^{\circ} \mathrm{C} \pm 11^{\circ} \mathrm{C}$ and contact pressure $0.7 \mathrm{MPa} \pm 0.05 \mathrm{MPa}$. During test, the wheel runs to and fro at frequency of 42 passes $/ \mathrm{min} \pm 1$ pass $/ \mathrm{min}$. Dynamic stability (DS) indicating the passes to achieve every $1 \mathrm{~mm}$ of deformation was used to evaluate the rutting resistance of asphalt mixture, as shown in equation (1). Specimens of $300 \mathrm{~mm}$ length and $300 \mathrm{~mm}$ width by $50 \mathrm{~mm}$ thick were prepared for the test. At least four replicates were tested for each fiber combination:

$$
\mathrm{DS}=\frac{\left(t_{2}-t_{1}\right) \times N}{d_{2}-d_{1}} \times C_{1} \times C_{2},
$$

where $d_{1}$ and $d_{2}$ correspond to the deformation at time $t_{1}$ and $t_{2}$, respectively; $C_{1}$ and $C_{2}$ are test parameters based on equipment model and sample dimension, as standard test equipment and samples are used in this study, $C_{1}=1.0$, $C_{2}=1.0$; and $N$ is the passes per min.

Figure 5 displays the change of DS with fiber combinations. First of all, specimens with fibers outperform the control group in general. Secondly, mixtures with higher

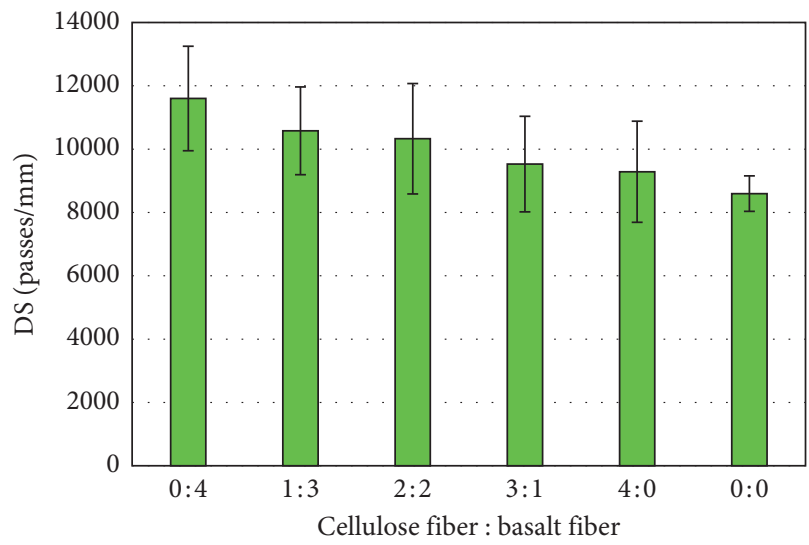

Figure 5: DS of SMA with different fiber combinations.

basalt fiber portions had higher DS values, indicating that basalt fiber improves the rutting resistance more significantly. As the permanent deformation performance of different fiber combinations looks close to each other, a onetail $t$ test was carried out to check the difference between different fiber combinations. The null hypothesis was that the DS of different fiber combinations were the same. The $P$ value was calculated and compared with the critical value of 0.05 to reject or accept the null hypothesis. In this study, $P \leq 0.05$ means the results of different fiber combinations are statistically different. Table 6 shows that only one case (cellulose : basalt $=0: 4$ against cellulose: basalt $=0: 0$ ) shows significance $(P=0.048)$, meaning that when only basalt fiber is added, the difference of DS are significantly different from the control group. Basalt fiber has very high modulus and tensile strength. When blended in SMA, it forms a strong fiber network and restricted the movement of mastic and thus improves the antideformation ability of asphalt mixture. Another reason for the nonsignificant improvement of DS by the other fiber combinations is that when cellulose is added, asphalt content is increased at the same time, which has the potential of increasing permanent deformation at high temperatures. In general, the addition of fibers can improve permanent deformation resistance of asphalt mixture, but the effects are not significant. 
TABle 6: $P$ values of draindown of different fiber combinations.

\begin{tabular}{lcccccc}
\hline Cellulose : basalt & $0: 4$ & $1: 3$ & $2: 2$ & $3: 1$ & $4: 0$ & $0: 0$ \\
\hline $0: 4$ & - & 0.229 & 0.205 & 0.092 & 0.078 & $\mathbf{0 . 0 4 8}$ \\
$1: 3$ & - & - & 0.427 & 0.212 & 0.175 & 0.053 \\
$2: 2$ & - & - & - & 0.290 & 0.244 & 0.121 \\
$3: 1$ & - & - & - & - & 0.429 & 0.195 \\
$4: 0$ & - & - & - & - & - & 0.277 \\
$0: 0$ & - & - & - & - & - & - \\
\hline
\end{tabular}

3.4. Low-Temperature Performance Test. As environmental temperature drops, the body of pavement would contract and internal stress builds up. If this contraction occurs fast enough, tensile stress accumulates in asphalt mixture and may cause cracking. Three-point beam test was carried out at $-10^{\circ} \mathrm{C} \pm 0.5^{\circ} \mathrm{C}$ to check bending resistance at low temperature as per JTG E20-2011(29). A loading is exerted at the midpoint of the beam at a speed of $50 \mathrm{~mm} / \mathrm{min}$. The specimen is $250 \mathrm{~mm}$ long $\times 30 \mathrm{~mm}$ wide $\times 35 \mathrm{~mm}$ high, with a supporting span of $200 \mathrm{~mm}$. The deflection strength $R_{B}$, maximum tensile strain $\varepsilon_{B}$ at the bottom of beam, and stiffness modulus $S_{B}$ are calculated as follows:

$$
\begin{gathered}
R_{B}=\frac{3 L P_{B}}{2 b h^{2}}, \\
\varepsilon_{B}=\frac{6 h d}{L^{2}}, \\
S_{B}=\frac{R_{B}}{\varepsilon_{B}},
\end{gathered}
$$

where $L$ is the supporting span, $P_{B}$ is the maximum load $(\mathrm{N})$, $b$ is the width of the beam, $h$ is the height of the beam, and $d$ is the maximum deflection (at the loading point). $R_{B}, \varepsilon_{B}$, and $S_{B}$ of different fiber combinations are listed in Table 7.

It is found that, with the increase of basalt fiber, $R_{B}$ and $S_{B}$ increase, while $\varepsilon_{B}$ decreases. On the contrary, as more cellulose is added, $R_{B}$ and $S_{B}$ decrease, while $\varepsilon_{B}$ increases. This is due to the different mechanisms of the two fibers. Basalt fiber is a strong material with very high modulus, the fibers form interconnected three-dimensional network and helps transfer the internal stresses, thus increasing the stiffness of SMA, acting like the reinforcing bar. The main effect of cellulose is increasing the asphalt content, which is believed to increase the ductility of samples. To avoid lowtemperature cracking, the asphalt mixture is required to either relax fast to release the stress or be strong enough to resist the stress. The introduction of both cellulose and basalt fiber at the same time seems to increase the deflection strength and ductility at the same time, resulting in a more balanced asphalt mixture. For example, in the case of cellulose: basalt $=3: 1$, when compared with the control group (cellulose: basalt $=0: 0$ ), it increases the $\varepsilon_{B}$ by about $5.3 \%$ from 3397 to 3575 as well as increases $R_{B}$ by about $7.1 \%$ from 11.31 to 12.11 .

3.5. Beam Fatigue Test. Intermediate temperature fatigue cracking by repeated loading is the one of the major distresses of asphalt pavement. Many test methods such as beam fatigue, semicircle beam (SCB), indirect tension (IDT) strength, Texas overlay tester (OT), and asphalt mixture performance tester (AMPT) have been used to characterize the resistance of asphalt mixtures to cracking.

One of the most widely accepted methods is the repeated loading beam fatigue test. Beam specimens with dimension of $380 \mathrm{~mm}$ long $\times 63 \mathrm{~mm}$ wide $\times 50 \mathrm{~mm}$ thick were subjected to four-point bending by IPC ${ }^{\circledR}$ fatigue test apparatus, as per ASTM D7460 [30]. Test temperature was set at $15^{\circ} \mathrm{C} \pm 0.5^{\circ} \mathrm{C}$. Haversine loading with controlled stress was conducted at a frequency of $10 \mathrm{~Hz} \pm 0.1 \mathrm{~Hz}$. Stress levels to flexural strength was set in four levels: $0.2,0.3,0.4$, and 0.5 . Before the fatigue test, flexural strength of beam was determined and correspondingly the stress levels. At least four replicates were tested for each stress level. Typical fatigue relation is stated as follows:

$$
\lg \left(N_{f}\right)=a-b \lg (\sigma)
$$

where $N_{f}$ is the fatigue repetition; $\sigma$ is stress level; and $a$ and $b$ are regression parameters.

Fatigue curves on log-log scale are shown in Figure 6. The strength test results and fatigue equations are listed in Table 8.

The fatigue models in this study have not been calibrated with field data, so they cannot be used to predict fatigue life. But, they are able to provide a comparison between specimens to evaluate the effects of different fiber combinations on fatigue. It is clearly shown that, as the stress level increased, the fatigue life declined. Overall, specimens with fiber had better fatigue than the control group. With the increase in the cellulose portion, the specimen demonstrated higher flexural strength and better fatigue property. This is mainly because of the increase of asphalt content. The slope of the fatigue line is an indication of sensitivity to stress level. Smaller slope means less sensitive to stress level. As indicated by parameter $b$ in fatigue equations in Table 8 , the slope decreased with the increase of basalt fiber. This makes sense as the basalt fiber forms a strong fiber network that helps mitigate the propagation of cracks to make asphalt mixtures more stable. As a result, a combination of cellulose and basalt fiber would lead to higher bending strength and better fatigue compared with sole basalt fiber and less stress sensitivity compared with sole cellulose.

3.6. Moisture Damage Test. The resistance of asphalt pavement to moisture damage is critical to its long-term performance and sustainability. A moisture test was conducted to evaluate moisture resistance of asphalt mixture with different fiber combinations as per ASTM D4867M [31]. 8 samples were prepared for each fiber combination and evenly divided into two groups: wet subset and dry subset. A freeze-thaw conditioning was employed for the wet subset samples: the specimens were first saturated in a vacuum chamber to reach a partial saturation of $55 \% \sim 80 \%$ and then wrapped in leak-proof bag with about $3 \mathrm{ml}$ distilled water and placed in an air bath freezer at $-18^{\circ} \mathrm{C}^{\circ} \pm 2.0^{\circ} \mathrm{C}$ for at least $15 \mathrm{~h}$; after that, the specimens were immersed in a water bath 
TABLE 7: Three-point beam tests at low temperature.

\begin{tabular}{lccccccc}
\hline Cellulose: basalt & OAC $(\%)$ & $P_{B}(\mathrm{~N})$ & $d(\mathrm{~mm})$ & $R_{B}(\mathrm{MPa})$ & $\varepsilon_{B}(\mu \varepsilon)$ & $S_{B}(\mathrm{MPa})$ & $\mathrm{Critical} \varepsilon_{B}(\mu \varepsilon)$ \\
\hline $0: 4$ & 6.0 & 1531 & 0.626 & 12.97 & 3287 & 3947 & 3783 \\
$1: 3$ & 6.0 & 1505 & 0.631 & 12.53 & 3313 & 3538 \\
$1: 1$ & 6.1 & 1454 & 0.661 & 12.28 & 3470 & 3388 \\
$3: 1$ & 6.1 & 1404 & 0.681 & 12.11 & 3575 & 3258 \\
$4: 0$ & 6.2 & 1352 & 0.693 & 11.85 & 3638 & 3329 \\
$0: 0$ & 5.4 & 1385 & 0.647 & 11.31 & 3397 & \\
\hline
\end{tabular}

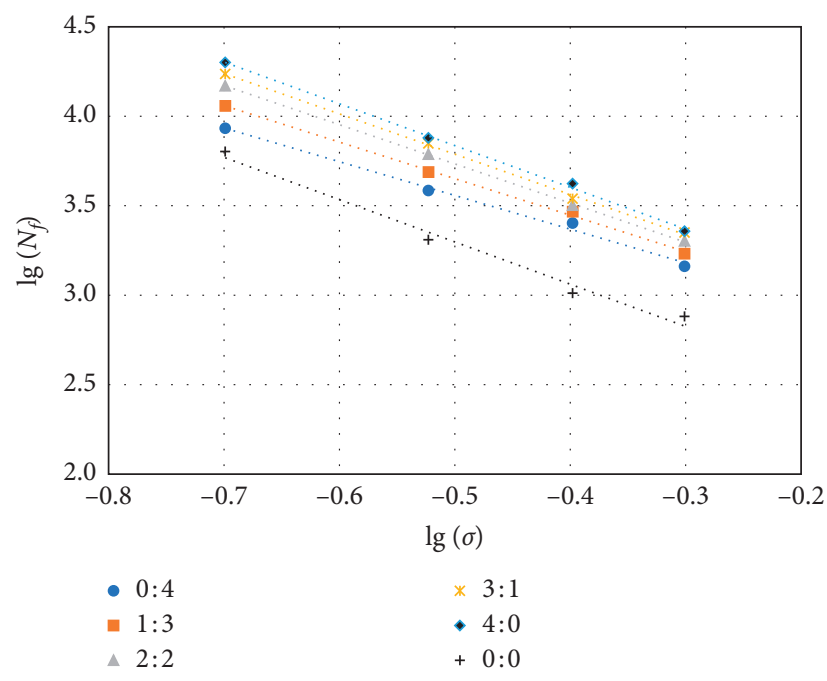

Figure 6: Fatigue curves of SMA with different fiber combinations.

TABLE 8: The strength and fatigue equations of SMA with different fiber combinations.

\begin{tabular}{lcll}
\hline Cellulose : Basalt & Flexural strength $(\mathrm{MPa})$ & Fatigue equations & $R^{2}$ \\
\hline $0: 4$ & 4.88 & $\lg \left(N_{f}\right)=2.6147-1.8858 \lg (\sigma)$ & 0.9914 \\
$1: 3$ & 5.35 & $\lg \left(N_{f}\right)=2.6308-2.0416 \lg (\sigma)$ & 0.9953 \\
$2: 2$ & 5.47 & $\lg \left(N_{f}\right)=2.6388-2.1904 \lg (\sigma)$ & 0.9980 \\
$3: 1$ & 6.90 & $\lg \left(N_{f}\right)=2.6615-2.2533 \lg (\sigma)$ & 0.9950 \\
$4: 0$ & 7.09 & $\lg \left(N_{f}\right)=2.6690-2.3346 \lg (\sigma)$ & 0.9930 \\
$0: 0$ & 4.17 & $\lg \left(N_{f}\right)=2.1162-2.3634 \lg (\sigma)$ & 0.9843 \\
\hline
\end{tabular}

at $60^{\circ} \mathrm{C}^{\circ} \pm^{\circ} 1.0^{\circ} \mathrm{C}$; at last, both the dry subset specimens and wet subset specimens were tested in the indirect tensile test. Moisture damage is indicated by the tensile strength ratio (TSR) of the wet subset $\left(\mathrm{S}_{\mathrm{tm}}\right)$ to that of the dry subset $\left(\mathrm{S}_{\mathrm{td}}\right)$, calculated from equations (4) and (5). The higher the residual strength is, the better the moisture stability is. Test results are listed in Table 9.

$$
\begin{array}{r}
S_{t}=\frac{2 P}{\pi t D}, \\
\mathrm{TSR}=\frac{S_{t m}}{s_{t d}},
\end{array}
$$

where $S_{t}$ is the tensile strength $(\mathrm{kPa}), P$ is the maximum load $(\mathrm{N}), t$ is the specimen height immediately before test $(\mathrm{mm})$, $D$ is specimen diameter $(\mathrm{mm}) . S_{t m}$ is the average strength of moisture conditioned subset $(\mathrm{kPa})$, and $S_{t d}$ is the average strength of dry subset $(\mathrm{kPa})$.
Asphalt mixtures with different cellulose-basalt fiber ratios showed different moisture resistances. With the increase in a portion of cellulose, the residual strength increased first and then began to decline. When cellulosebasalt fiber ratio reached $2: 2$, the moisture stability was the best. This is because of the composite effect of the asphalt absorption by cellulose and the strength enforcement by basalt fiber, which together improve the resistance to moisture. All cases with fiber have better moisture damage resistance than the control group.

3.7. Economy Analysis. The aforementioned technical analysis has demonstrated that cellulose and basalt fiber enhance SMA properties and performances in different ways and work as good complements for each other. Nevertheless, when applied in real projects, economy is a must consideration. In fact, one of the purposes of hybrid enforcement is to replace a portion of expensive basalt fiber with cheap 
TABLE 9: Moisture test of SMA with different fiber combinations.

\begin{tabular}{lccccc}
\hline Cellulose : basalt & Air voids (\%) & Degree of saturation $(\%)$ & Average $\underline{S_{t m}}(\mathrm{kPa})$ & Average $S_{t d}(\mathrm{kPa})$ & TSR $(\%)$ \\
\hline $0: 4$ & 6.9 & 64 & 498 & 548 & 90.8 \\
$1: 3$ & 6.6 & 60 & 497 & 537 & 92.4 \\
$2: 2$ & 7.2 & 71 & 597 & 640 & 704 \\
$3: 1$ & 6.3 & 78 & 646 & 677 & 91.7 \\
$4: 0$ & 7.7 & 73 & 602 & 89.2 \\
$0: 0$ & 7.5 & 68 & 347 & 416 \\
\hline
\end{tabular}

cellulose to bring down the cost. The costs of different fiber combinations and asphalt mixtures were calculated and are listed in Table 10. This case was based on average market price of China in 2018:4000 yuan/ton for cellulose, 10000 yuan/ton for basalt fiber, and 6000 yuan/ton for SBS modified asphalt. The unit price of fiber combination was calculated by multiplying the unit price of each fiber and its portion, as displayed in column 2. The total amount of fiber was set at $0.4 \%$ of asphalt mixture by weight, and the cost of hybrid fibers was displayed in column 3 . The total cost (hybrid fiber + asphalt) was displayed in the last column, regardless of aggregates.

As the table shows, with the increase in cellulose, the cost of fiber decreases as less basalt fiber was used. Correspondingly, the cost of asphalt goes up a little as a result of higher asphalt content. The net effect is that the total cost declines with more cellulose. As a result, the hybrid fiber has a price advantage over sole basalt fiber.

To get an optimum fiber combination, the benefit-cost ratio $B$ is termed as the ratio of "percent performance change" to "percent cost change." Obviously, the bigger the $B$ is, the more the cost-effective it is:

$$
B=\frac{P}{C}
$$

where $P$ is the percent performance change and $C$ is the percent cost change.

The $B$ values of different fiber combinations for different characteristics based on the results of this study are listed in Table 11. As is shown in the table, the $B$ value of different performances shows different trends. For draindown and fatigue, $B$ value increases as cellulose increases; but for permanent deformation, $B$ value decreases as cellulose increase. For moisture damage, $B$ value increases first and then declines. This would bring in conflicts when performances with opposite $B$ trends are needed at the same time, e.g., a fiber combination that achieves higher $B$ value in permanent deformation would result in a lower $B$ value in fatigue. Asphalt pavement in service is subjected to traffic and environmental change, and an optimum fiber combination is to produce SMA with balanced characteristics to improve all required performances. One simple and effective solution is to assign different weight coefficients to different performances to get a comprehensive $B$ value, $B_{\text {total }}$ :

$$
B_{\text {total }}=\sum w_{i} B_{i}
$$

where $w_{i}$ is the weight coefficient, $\sum w_{i}=1 ; w_{i}$ is determined based on traffic, environmental condition, pavement structure, etc; and $B_{i}$ is the $B$ value for the $i$ th characteristic.
In general, replacing some basalt fiber with cellulose would bring down the price and improve the fatigue and draindown at the same time. In this study, the moisture damage indicates that the best moisture resistance is achieved when the portion of cellulose and basalt fiber is equal. For specific projects, designers can determine the weight coefficient and calculate an economic combination of fibers in accordance with equation (7).

\section{Discussions}

Cellulose and basalt fiber are widely used additives to improve the asphalt mixture performance, especially SMA. This study showed that, when used in good proportion, the combination of cellulose and basalt fiber can lead to a more balanced performance.

This study has three main parts. The first part was material tests, which revealed basic properties including advantages and disadvantages of the two fibers. Basalt fiber had much better high temperature stability than cellulose. The mass loss of cellulose was nearly 20 times that of basalt fiber. At the same time, thanks to its porous and ribbon type surface, the absorption of cellulose was more than 5 times that of basalt fiber. Results from the $\mathrm{pH}$ test showed that both fibers were weak alkaline. Stripping test and microscope electric scanning demonstrated that bond between cellulose and asphalt cement was better than that of basalt fiber. From these material properties, it is hypothesized that the two fibers can serve as a complement to each other to balance the performance of asphalt mixtures.

A series of performance tests were conducted in the second part to validate the hypothesis. Combinations of different cellulose-basalt fiber portions were introduced into SMA13. The total amount of fiber addition is set at $0.4 \%$ of asphalt mixture by weight, in accordance with relevant literature. Five portions $0: 4,1: 3,2: 2,3: 1$, and $4: 0$ as well as a control group $(0: 0)$ without any fiber were designed, and $\mathrm{OAC}$ was determined for each combination. With the increase in the cellulose, the OAC increased mainly because of the high absorption of cellulose. Volumetric properties changed as a result of the different asphalt content and fiber volumetric properties. The draindown tests showed that cellulose has a more significant influence on draindown. Performance tests including permanent deformation, low temperature bending, fatigue, and moisture damage were evaluated and compared. The mechanisms of the two fibers were also analyzed. The addition of cellulose fiber mainly increases asphalt content, increasing the fatigue performance and ductility at low temperature, whilst basalt fiber 
TABLE 10: Costs of hybrid fibers and asphalt for 1 ton SMA with different fiber combinations.

\begin{tabular}{lcccccc}
\hline $\begin{array}{l}\text { Cellulose: } \\
\text { basalt }\end{array}$ & $\begin{array}{c}\text { Unit price of hybrid fiber } \\
\text { (yuan/ton) }\end{array}$ & $\begin{array}{c}\text { Cost of hybrid fiber } \\
\text { (yuan/ton) }\end{array}$ & $\begin{array}{c}\text { OAC } \\
(\%)\end{array}$ & $\begin{array}{c}\text { Unit price of asphalt } \\
\text { (yuan/ton) }\end{array}$ & $\begin{array}{c}\text { Cost of asphalt } \\
\text { (yuan/ton) }\end{array}$ & $\begin{array}{c}\text { Total cost } \\
\text { (yuan/ton) }\end{array}$ \\
\hline $0: 4$ & 10000 & 40 & 5.98 & 6000 & 338.4 & 378.4 \\
$1: 3$ & 8500 & 34 & 6.02 & 6000 & 340.8 & 374.8 \\
$2: 2$ & 7000 & 28 & 6.06 & 6000 & 346.6 & 370.6 \\
$3: 1$ & 5500 & 22 & 6.12 & 6000 & 348.2 \\
$4: 0$ & 4000 & 16 & 6.17 & 6000 & 367.6 \\
$0: 0$ & 0 & 0 & 5.41 & 6000 & 307.8 \\
\hline
\end{tabular}

TABle 11: Benefit-cost ratio of different fiber combinations for different characteristics.

\begin{tabular}{lccccc}
\hline Cellulose : basalt fiber & Draindown & Permanent deformation & Low-temperature strain & Fatigue & Moisture damage \\
\hline $0: 4$ & 2.118 & 1.524 & -0.142 & 3.845 & 0.387 \\
$1: 3$ & 2.625 & 1.060 & -0.114 & 6.377 & 0.496 \\
$2: 2$ & 3.081 & 0.988 & 0.106 & 9.827 & 0.576 \\
$3: 1$ & 3.786 & 0.553 & 0.268 & 12.492 & 0.507 \\
$4: 0$ & 4.180 & 0.435 & 0.385 & 14.659 & 0.364 \\
\hline
\end{tabular}

works like reinforcement bars in the asphalt mixture due to it high strength and modulus. As a result, it improves the permanent deformation significantly and increases the deflection strength at low temperature but does not increase the fatigue much. However, due to its enforcement, the addition off basalt fiber improved the stress sensitivity of fatigue. As for moisture damage resistance, the combination of the two fibers with equal proportion showed the best performance. Although differences exist among different fiber combinations, SMA with fiber overall outperformed the control group in all tests. As the mechanisms of the two fibers are different, they have effects on different aspects of performance of asphalt mixture. Hybrid modification with cellulose and basalt fiber in asphalt mixture can produce more balanced asphalt mixture performances than adding only one fiber. A good example is shown in the low-temperature test that the addition of cellulose and basalt fiber increases the ductility and deflection strength at the same time. Another good demonstration is the fatigue test, in which the addition of cellulose increases fatigue resistance and the basalt fiber decreases stress sensitivity.

In the third part, economy was taken into consideration, as normally, the price of basalt fiber is over twice as much as cellulose. The increase of cellulose would increase the cost of asphalt, but the total cost is still much lower compared with that of basalt fiber. To help identify the optimum fiber combination, the benefit-cost ratio $B$ was introduced to take into account the performance improvement with regard to cost. Altogether, compared with solely basalt fiber modification, hybrid modification with both cellulose fiber and basalt fiber can reduce the cost and improve the performance at the same time.

\section{Conclusions}

Cellulose and basalt fibers were introduced to SMA simultaneously to investigate the performance improvement through a series of laboratory tests. Main conclusions are as follows:
(1) Cellulose fiber and basalt fiber have different material properties, and the basalt fiber has better high temperature stability while cellulose fiber has better absorption and bond with asphalt due to its porous surface.

(2) The two fibers improve different aspects of SMA performance. Cellulose fiber improves drain down, ductility, and fatigue significantly; at the same time, basalt fiber contributes mainly on the improvement of permanent deformation, deflection strength, and stress sensitivity of fatigue. The existence of both basalt fiber and cellulose fiber improve the moisture damage resistance.

(3) The mechanism of the two fibers is different. Addition of cellulose increases the asphalt content as well as its bond of the asphalt mixture. Basalt fiber, due to its good mechanical property of high strength and modulus, acts like reinforcement in the asphalt mixture.

(4) The hybrid modification of SMA using cellulose fiber and basalt fiber can achieve a more balanced performance at an economical cost.

\section{Data Availability}

The data used to support the study are available upon request from the corresponding author through e-mail (805296712@ qq.com).

\section{Conflicts of Interest}

The authors declare that there are no conflicts of interest regarding the publication of this paper.

\section{Acknowledgments}

This study was funded by the National Key R\&D Program Projects of China (2018YFB1600200); National Natural 
Science Foundation of China (51678078); Natural Science Foundation of Hunan Province (2020JJ5578), and China Scholarship Council (201608430123).

\section{References}

[1] R. S. McDaniel, NCHRP Synthesis 475: Fiber Additives in Asphalt Mixtures: A Synthesis of Highway Practice, Transportation Research Board, Washington, DC, USA, 2015.

[2] P. Peltonen, "Wear and deformation of characteristics of fiber reinforced asphalt pavements," Construction and Building Materials, vol. 5, no. 1, pp. 18-22, 1991.

[3] A. Mahrez, M. Karim, and H. Katman, "Prospect of using glass fiber reinforced bituminous mixes," Journal of the Eastern Asia Society for Transportation Studies, vol. 5, pp. 794-807, 2003.

[4] R. L. Fitzgerald, "Novel applications of carbon fiber for hot mix asphalt reinforcement and carbon-carbon pre-forms," MSc Thesis, Department of Chemical Engineering, Michigan Technological University, Houghton, MI, USA, 2000.

[5] M. Guo and Y. Tan, "Interaction between asphalt and mineral fillers and its correlation to mastics' viscoelasticity," International Journal of Pavement Engineering, pp. 1-10, 2019.

[6] S. Wu, Q. Ye, N. Li, and H. Yue, "Effects of fibers on the dynamic properties of asphalt mixtures," Journal of Wuhan University of Technology-Material (Science Edition), vol. 22, no. 4, pp. 733-736, 2007.

[7] M. Guo, H. Liu, Y. Jiao et al., "Effect of WMA-RAP technology on pavement performance of asphalt mixture: a state-of-theart review," Journal of Cleaner Production, vol. 266, Article ID 121704, 2020.

[8] Y. Tan and M. Guo, "Using surface free energy method to study the cohesion and adhesion of asphalt mastic," Construction and Building Materials, vol. 47, pp. 254-260, 2013.

[9] Y. Zheng, Y. Cai, G. Zhang, and H. Fang, "Fatigue property of basalt fiber-modified asphalt mixture under complicated environment," Journal of Wuhan University of Technology-Material (Science Edition), vol. 29, no. 5, pp. 996$1004,2014$.

[10] S. Tapkin, "The effect of polypropylene fibers on asphalt performance," Building and Environment, vol. 43, no. 6, pp. 1065-1071, 2008.

[11] H. Taherkhani, "Investigating the effects of nanoclay and nylon fibers on the mechanical properties of asphalt concrete," Civil Engineering Infrastructure Journal, vol. 49, no. 2, pp. 235-249, 2016.

[12] J. J. Stempihar, M. I. Souliman, and K. E. Kaloush, "Fiberreinforced asphalt concrete as sustainable paving material for airfields," Transportation Research Record: Journal of the Transportation Research Board, vol. 2266, no. 1, pp. 60-68, 2012.

[13] E. R. Brown, R. B. Mallick, J. E. Haddock, and J. Bukowski, "Performance of stone matrix asphalt (SMA) mixtures in the United States," NCAT Report No.97-1, National Center for Asphalt Technology, Auburn, AL, USA, 1997.

[14] E. R. Brown, J. E. Haddock, R. B. Mallick, and T. Lynn, "Development of A Mixture design procedure for stone matrix asphalt (SMA)," NCAT Report No.97-3, National Center for Asphalt Technology, Auburn, AL, USA, 1997.

[15] H. Chen and Q. Xu, "Experimental study of fibers in stabilizing and reinforcing asphalt binder," Fuel, vol. 89, no. 7, pp. 1616-1622, 2010.
[16] Q. Ye and S. Wu, "Rheological properties and fiber reinforced asphalt binders," Indian Journal of Engineering and Materials Sciences, vol. 16, no. 2, pp. 93-99, 2009.

[17] Y. Decoene, "Contribution of cellulose fibers to the performance of porous asphalts," Transportation Research Record: Journal of the Transportation Research Board, vol. 1265, pp. 82-86, 1990.

[18] L. A. Cooley Jr., E. R. Brown, and D. E. Watson, "Evaluation of open-graded friction course mixtures containing cellulose fibers," Transportation Research Record: Journal of the Transportation Research Board, vol. 1723, pp. 19-25, 2000.

[19] K. D. Stuart and P. Malmquist, "Evaluation of using different stabilizers in US route 15 (Maryland) stone matrix asphalt," Transportation Research Record: Journal of the Transportation Research Board, vol. 1454, pp. 48-57, 1994.

[20] K. Singha, "A short review on basalt fiber," International Journal of Textile Science, vol. 1, no. 4, pp. 19-28, 2012.

[21] N. Morova, "Investigation of usability of basalt fibers in hot mix asphalt concrete," Construction and Building Materials, vol. 47, pp. 175-180, 2013.

[22] ASTM D3800-16, Standard Test Method for Density of HighModulus Fibers, ASTM International, West Conshohocken, PA. USA, 2016.

[23] ASTM D5034-17, Standard Test Method for Breaking Strength and Elongation of Textile Fabrics (Grab Test), ASTM International, West Conshohocken, PA, USA, 2017.

[24] S. M. Abtahi, M. Sheikhzadeh, and S. M. Hejazi, "Fiberreinforced asphalt-concrete - a review," Construction and Building Materials, vol. 24, no. 6, pp. 871-877, 2010.

[25] G. R. Hicks, Moisture Damage in Asphalt Concrete, Transportation Research Board, National Research Council, Washington, DC, USA, 1991.

[26] JTG F40-2017, Technical Specification For Construction Of Highway Asphalt Pavements, China Communications Press, Beijing, China, 2017.

[27] JT/T 533-2004, Plant Fibers Used in Asphalt Pavements, China Communications Press, Beijing, China, 2004.

[28] ASTM (D6390-11), Standard Test Method for Determination of Draindown Characteristics in Uncompacted Asphalt Mixtures, ASTM, West Conshohocken, USA, 2017.

[29] JTE E20-2011, Standard Test Methods of Binder and Bituminous Mixtures for Highway Engineering, China Communications Press, Beijing, China, 2011.

[30] ASTM (D7460-10), Standard Test Method for Determining Fatigue Failure of Compacted Asphalt Concrete Subjected to Repeated Flexure Bending, ASTM, West Conshohocken, USA, 2010.

[31] ASTM (D4867M-09), Standard Test Method for Effect of Moisture on Asphalt Concrete Paving Mixtures, ASTM, West Conshohocken, USA, 2014. 